\title{
Content and Face Validity and Feasibility of 5 Candidate Instruments for Psoriatic Arthritis Randomized Controlled Trials: The PsA OMERACT Core Set Workshop at the GRAPPA 2017 Annual Meeting
}

\author{
Richard Holland, William Tillett, Alexis Ogdie, Ying Y. Leung, Dafna D. Gladman, \\ Kristina Callis Duffin, Laura C. Coates, Philip J. Mease, Lihi Eder, Vibeke Strand, \\ Musaab Elmamoun, Pil Højgaard, Jeffrey Chau, Maarten de Wit, Niti Goel, Chris A. Lindsay, \\ Oliver FitzGerald, Bev Shea, Dorcas Beaton, and Ana-Maria Orbai
}

\begin{abstract}
The Group for Research and Assessment of Psoriasis and Psoriatic Arthritis (GRAPPA)-Outcome Measures in Rheumatology (OMERACT) Psoriatic Arthritis (PsA) Core Set working group is in the process of selecting core instruments for PsA clinical trials. During a 2-h workshop and breakout group discussions at the GRAPPA 2017 annual meeting in Amsterdam, the Netherlands, participants discussed the first set of candidate instruments to be taken through the OMERACT Filter 2.1 instrument selection process: 66/68 swollen/tender joint count (66/68JC), Spondyloarthritis Consortium of Canada (SPARCC) enthesitis index, patient's global assessment (GRAPPA and OMERACT formulations), Health Assessment Questionnaire-Disability Index (HAQ-DI), Psoriatic Arthritis Impact of Disease (PsAID) questionnaires 9 and 12, and Functional Assessment of Chronic Illness Therapy (FACIT) Fatigue. Based on the assessment of domain match (content and face validity) and feasibility according to the OMERACT instrument selection criteria, the working group recommends continuing with appraisal of construct validity and discrimination for 66/68JC, SPARCC, PsAID 9 and 12, HAQ-DI, and FACIT-Fatigue. In addition, it recommends repeating the OMERACT Filter 2.1 process for patient global instruments because of insufficient votes. Additional sets of candidate instruments for the PsA core instrument set will be evaluated in a similar process. (J Rheumatol Suppl. 2018 June;94:17-25; doi:10.3899/jrheum.180142)
\end{abstract}

Key Indexing Terms:

PSORIATIC ARTHRITIS

GRAPPA

OUTCOME MEASURES IN RHEUMATOLOGY

CORE SET

From the Royal Prince Alfred Hospital Medical Centre, Sydney, Australia; Royal National Hospital for Rheumatic Diseases, Bath, UK; University of Pennsylvania, Philadelphia, Pennsylvania, USA; Department of Rheumatology and Immunology, Singapore General Hospital, Singapore; University of Toronto, Krembil Research Institute, Psoriatic Arthritis Program, University Health Network, Toronto, Ontario, Canada; Department of Dermatology, University of Utah, Salt Lake City, Utah, USA; University of Oxford, Oxford, UK; Swedish Medical Center and University of Washington School of Medicine, Seattle, Washington, USA; Women's College Research Institute, Women's College Hospital, University of Toronto, Toronto, Ontario, Canada; Division of

Immunology/Rheumatology, Stanford University, Palo Alto, California, USA; Department of Rheumatology, St. Vincents University Hospital and Conway Institute for Biomolecular Research, University College Dublin, Dublin, Ireland; The Parker Institute, Bispebjerg and Frederiksberg Hospital, The Capital Region of Denmark; Hong Kong Psoriatic Arthritis Association, Hong Kong, China; VU Medical Centre, Amsterdam, the Netherlands; IQVIA, Duke University School of Medicine, Durham, North Carolina, USA; School of Epidemiology, Public Health, and Preventive Medicine, Faculty of Medicine, University of Ottawa, and Ottawa Hospital Research Institute, Clinical Epidemiology Program, Ottawa, Ontario, Canada; Musculoskeletal Health and Outcomes Research, St. Michael's
Hospital and Institute for Work and Health, and Department of Occupational Science and Occupational Therapy, Rehabilitation Sciences Institute, and the Institute for Health Policy Management and Evaluation, University of Toronto, Toronto, Ontario, Canada; Division of Rheumatology, Johns Hopkins University School of Medicine, Baltimore, Maryland, USA.

As part of the supplement series GRAPPA 2017, this report was reviewed internally and approved by the Guest Editors for integrity, accuracy, and consistency with scientific and ethical standards.

The PsA Core Set patient research partner pre-meeting was supported by a research grant from Novartis to GRAPPA. AMO is funded in part by grants from the US National Institutes of Health (P30 AR070254-01), the Rheumatology Research Foundation (RRF Scientist Development Award), and the Staurulakis Discovery Award.

R. Holland, MB ChB, Royal Prince Alfred Hospital Medical Centre W. Tillett, BSc, MB ChB, PhD, MRCP, Royal National Hospital for Rheumatic Diseases; A. Ogdie, MD, MSCE, University of Pennsylvania; Y.Y. Leung, MB ChB, MD, Department of Rheumatology and Immunology, Singapore General Hospital, Singapore; D.D. Gladman, MD, FRCPC, Professor of Medicine, University of Toronto, Senior Scientist, Krembil Research Institute, Director, Psoriatic Arthritis Program, University

Personal non-commercial use only. The Journal of Rheumatology Copyright (c) 2018. All rights reserved. 
Health Network; K. Callis Duffin, MD, MS, Department of Dermatology, University of Utah; L.C. Coates, $M B C h B, P h D$, University of Oxford; P.J. Mease, MD, Rheumatology Research, Swedish Medical Center and University of Washington School of Medicine; L. Eder, MD, PhD, Women's College Research Institute, Women's College Hospital, University of Toronto; V. Strand, MD, Division of Immunology/Rheumatology, Stanford University; M. Elmamoun, MBBS, MRCPI, Department of Rheumatology, St. Vincents University Hospital and Conway Institute for Biomolecular Research, University College Dublin; P. Højgaard, MD, The Parker Institute, Bispebjerg and Frederiksberg Hospital; J. Chau, BA, MCS, Patient Research Partner, Hong Kong Psoriatic Arthritis Association; M. de Wit, PhD, Patient Research Partner, VU Medical Centre; N. Goel, MD, Patient Research Partner, IQVIA, Duke University School of Medicine; C.A. Lindsay, PharmD, Patient Research Partner; O. FitzGerald, MD, FRCPI, FRCP(UK), Newman Clinical Research Professor, Department of Rheumatology, St. Vincents University Hospital and Conway Institute for Biomolecular Research, University College Dublin; B. Shea, School of Epidemiology, Public Health, and Preventive Medicine, Faculty of Medicine, University of Ottawa, and Ottawa Hospital Research Institute, Clinical Epidemiology Program; D. Beaton, BScOT, PhD, Musculoskeletal Health and Outcomes Research, St. Michael's Hospital and Institute for Work and Health, and Department of Occupational Science and Occupational Therapy, Rehabilitation Sciences Institute, and the Institute for Health Policy Management and Evaluation, University of Toronto; A.M. Orbai, MD, MHS, Division of Rheumatology, Johns Hopkins University School of Medicine.

Address correspondence to Dr. A.M. Orbai, Assistant Professor of Medicine, Director Psoriatic Arthritis Program, Johns Hopkins University School of Medicine, Division of Rheumatology, 5200 Eastern Ave., MFL Center Tower, Suite 4100, Baltimore, Maryland 21224, USA. E-mailaorbai1@jhmi.edu

Psoriatic arthritis (PsA) randomized controlled trials (RCT) measure many outcomes to assess the safety and efficacy of interventions on multiple disease-specific manifestations ${ }^{1}$. The Group for Research and Assessment of Psoriasis and Psoriatic Arthritis (GRAPPA), in collaboration with Outcome Measures in Rheumatology (OMERACT), developed the first core set of domains to be measured in PsA RCT in $2006^{2}$ to standardize the measurement of outcomes across PsA RCT. The PsA core domain set was updated to reflect both patient and physician priorities for PsA domains and to fulfill OMERACT Filter 2.0 criteria for domain selection $3,4,5$. OMERACT endorsed the updated PsA core domain set in $2016^{6}$. The updated PsA core domain set includes musculoskeletal (MSK) disease activity, skin disease activity, pain, patient's global assessment (PtGA), physical function, health-related quality of life, fatigue, and systemic inflammation.

The GRAPPA-OMERACT PsA working group is currently developing a PsA core instrument set to guide the selection of outcome measures for PsA RCT. The Core Outcome Measures for Psoriatic Arthritis Clinical Trials (COMPACT) study will guide this process and comprises several international work streams ${ }^{7}$ with 2 key aims: to identify candidate instruments to measure the PsA core domain set, and to retain instruments that meet OMERACT Filter 2.1 standards (which rely on evidence-based appraisal of candidate instruments using criteria for content validity, feasibility, construct validity, and discrimination $)^{8}$. Candidate instruments are being identified and their measurement properties appraised in systematic literature reviews by members of the working group ${ }^{9}$ and additional evidence on construct validity and discrimination is being obtained from RCT and longterm observational studies (LOS). This evidence will be synthesized and a decision reached as to whether each instrument passes the Filter 2.1 for use in the target trials/research.

\section{OMERACT Filter 2.1 Process Applied to PsA Core Instrument Selection}

A comprehensive list of instruments used in PsA RCT and LOS was drafted in May 2017 based on systematic literature reviews and expanded upon with input from the working group (Supplementary Table 1, available with the online version of this article). The working group began the OMERACT instrument selection process with all participants at the GRAPPA 2017 annual scientific meeting with the aim of obtaining feedback on the OMERACT process and the content validity and feasibility of preselected instruments. Prior to the GRAPPA 2017 annual meeting, steering group members $(n=13)$ discussed the instruments, and a steering group survey was conducted to select 1 candidate instrument for each core domain (except pain, which is the focus of the Pain OMERACT working group; and skin disease activity, which is the focus of International Dermatology Outcome Measures).

At the GRAPPA core instrument set workshop, the working group began the first 2 steps of the instrument selection process. Six breakout groups discussed the following domain-instrument pairs: (1) MSK disease activity arthritis: 66/68 swollen/tender joint count (SJC/TJC) ${ }^{10}$; (2) MSK disease activity enthesitis: Spondyloarthritis Consortium of Canada (SPARCC) Enthesitis Index ${ }^{11}$; (3) PtGA: OMERACT ${ }^{5}$ and GRAPPA ${ }^{12}$ patient's global assessment visual analog scales; (4) physical function: Health Assessment Questionnaire-Disability Index (HAQ-DI) ${ }^{13}$; (5) health-related quality of life (HRQOL): Psoriatic Arthritis Impact of Disease questionnaires 9 and 12 (PsAID9, PsAID12) ${ }^{14}$; and (6) fatigue: Functional Assessment of Chronic Illness Therapy (FACIT) Fatigue ${ }^{15}$.

Four questions must be answered to ascertain whether an instrument has passed the OMERACT Filter 2.1. The assessment of face and content validity addresses the first question: Is the instrument a good match with the target domain? Participants [rheumatologists, dermatologists, patient research partners (PRP), industry representatives, rheumatology trainees] were asked for their opinions about whether there was sufficient overlap between the content of the domain intended to be measured and the information gathered by the instrument ${ }^{7}$. To illustrate domain content, the working group used domain definitions developed for the nominal group technique consensus meeting conducted as part of the PsA core domain set update ${ }^{4}$. These definitions, where relevant, were supplemented with patient quotes from international focus groups that described the domains from

Personal non-commercial use only. The Journal of Rheumatology Copyright @ 2018 . All rights reserved. 
the patient perspective ${ }^{4}$. Materials for use during the breakout groups included printouts of the instrument with instructions and an explanation of method of data collection and scoring, the domain to be measured, and additional domain content information such as patient descriptions so participants could compare and discuss domain content with instrument content (see Appendices 1, 2, and 3). In collaboration with PRP, the working group developed a booklet for PRP that contains OMERACT process information, domain definitions, and the instruments with details on their use and scoring. This booklet was distributed to PRP $(n=12) 2$ weeks prior to the meeting to optimize PRP participation in the meeting. Twelve PRP participated in 2 OMERACT Webinars conducted and organized by Dr. Maarten de Wit, an expert in participatory research, prior to the annual meeting to familiarize PRP with the instrument appraisal and selection process. Further, in a 4-h premeeting workshop, PRP were introduced to the OMERACT instrument selection process and instrument psychometric property appraisal. PRP then assessed 4 instruments using the OMERACT scoring system.

\section{GRAPPA Meeting PsA Core Instrument Set Workshop}

The PsA Core Instrument Set Workshop was structured into an introductory plenary session $(20 \mathrm{~min})$, followed by 6 breakout group discussions (60 min), and ending with a plenary session that reported initial results from the breakout groups (30 min). At the introductory session, Drs. Ana-Maria Orbai, Alexis Ogdie, Katy Leung, and William Tillett presented the COMPACT study and the OMERACT Filter 2.1 process. They also demonstrated the use of the OMERACT domain match (encompassing content and face validity) and the feasibility questionnaires for the patient-reported outcomes, such as the PsAID instrument. Working group members (1 moderator and 1 rapporteur) then facilitated 6 breakout groups that each focused on 1 PsA domain and 1 corresponding instrument. Meeting participants, including patients (with 2 PRP per group), clinicians, trialists, methodologists, and payers were spread evenly among the groups. PRP helped facilitate discussion and voting during the breakout sessions.

In each breakout group, facilitators introduced the domain definition and its corresponding instrument. Participants were then asked to review and discuss the preselected instrument and individually appraise the instrument by completing paper-based OMERACT questionnaires that examine domain match and feasibility. These anonymous questionnaires were collected at the end, and votes for each aspect of domain match and feasibility were centralized by instrument. At the conclusion of each breakout group, a global vote was taken from participants (through show of hands) on whether the assigned instrument met the requirements for domain match and feasibility using the OMERACT traffic-light scoring system for a final assessment (quantity, consistency, and performance on that property) of the available evidence for each measurement property (green: instrument meets requirements to proceed with collecting evidence for additional measurement properties; amber: there is concern, caution, or weakness, but the instrument is good enough to go forward; red: should not proceed, does not meet content validity and/or feasibility standards) ${ }^{5}$. Traditionally, OMERACT consensus is defined as more than $70 \%$ agreement within a group. The working group also examined majority agreement, defined as more than $50 \%$ agreement within a group. These levels of agreement then determined the strength of the evidence for the overall conclusion on domain match and feasibility based on these votes [evidence for domain match and feasibility being stronger (green level) if consensus vs majority (amber level) agreement was achieved].

Workshop outcome. There were 145 participants across all breakout groups. Anonymized votes on content validity and feasibility are summarized across groups and instruments in Table 1 and Table 2, respectively. There was a breakout group discussion on PtGA; however, only 2 participants completed the anonymized questionnaires in this group (data not reported because of this small number).

Domain match. More than $70 \%$ of participants in the respective breakout groups endorsed the PsA instrument $66 / 68 \mathrm{SJC} / \mathrm{TJC}$ as a good match with the target domain of MSK disease activity arthritis, the FACIT-Fatigue as a good match with Fatigue, and the PsAID12 as a good match with HRQOL. More than $50 \%$ of participants voted for SPARCC as a good match with MSK disease activity enthesitis and PsAID9 as a good match with HRQOL. There were concerns about the redundancy of items for PsAID9 and FACIT-Fatigue, where no majority vote was achieved (all options $<50 \%$ agreement). In addition, the working group noticed a significant spread of opinions regarding instrument redundancy in all groups. There were also concerns over the adequacy of content ["Have all important elements been included (consider breadth and depth needed)?"] for SPARCC, HAQ-DI, and PsAID9. The voting results suggest that a better description of elements and technique for the $66 / 68$ SJC/TJC may be helpful. There was consensus (> 70\% voted yes) that response options were adequate for the SPARCC, PsAID9, PsAID12, and FACIT-Fatigue, and majority agreement (> 50\% voted yes) for the $66 / 68 \mathrm{SJC} / \mathrm{TJC}$ and HAQ-DI. There was consensus ( $>70 \%$ voted yes) that scoring was adequate for the 66/68 SJC/TJC and SPARCC, and majority agreement (> 50\% voted yes) for the HAQ-DI. The vote was "uncertain" for adequacy of scoring (41-46\% voted yes, 38-50\% voted uncertain) for the PsAID9, PsAID12, and FACIT-Fatigue (Table 1).

Feasibility. There was consensus ( $>70 \%$ voted yes) that the 66/68 SJC/TJC, HAQ-DI, and FACIT-Fatigue were easy to understand and majority agreement (> 50\% voted yes) for both the PsAID9 and PsAID12. There was no consensus for SPARCC (note missing votes). Time to complete, method of

Personal non-commercial use only. The Journal of Rheumatology Copyright $\subset$ 2018 . All rights reserved. 
Table 1. GRAPPA meeting participants' ratings for OMERACT domain match questionnaires for each PsA instrument.

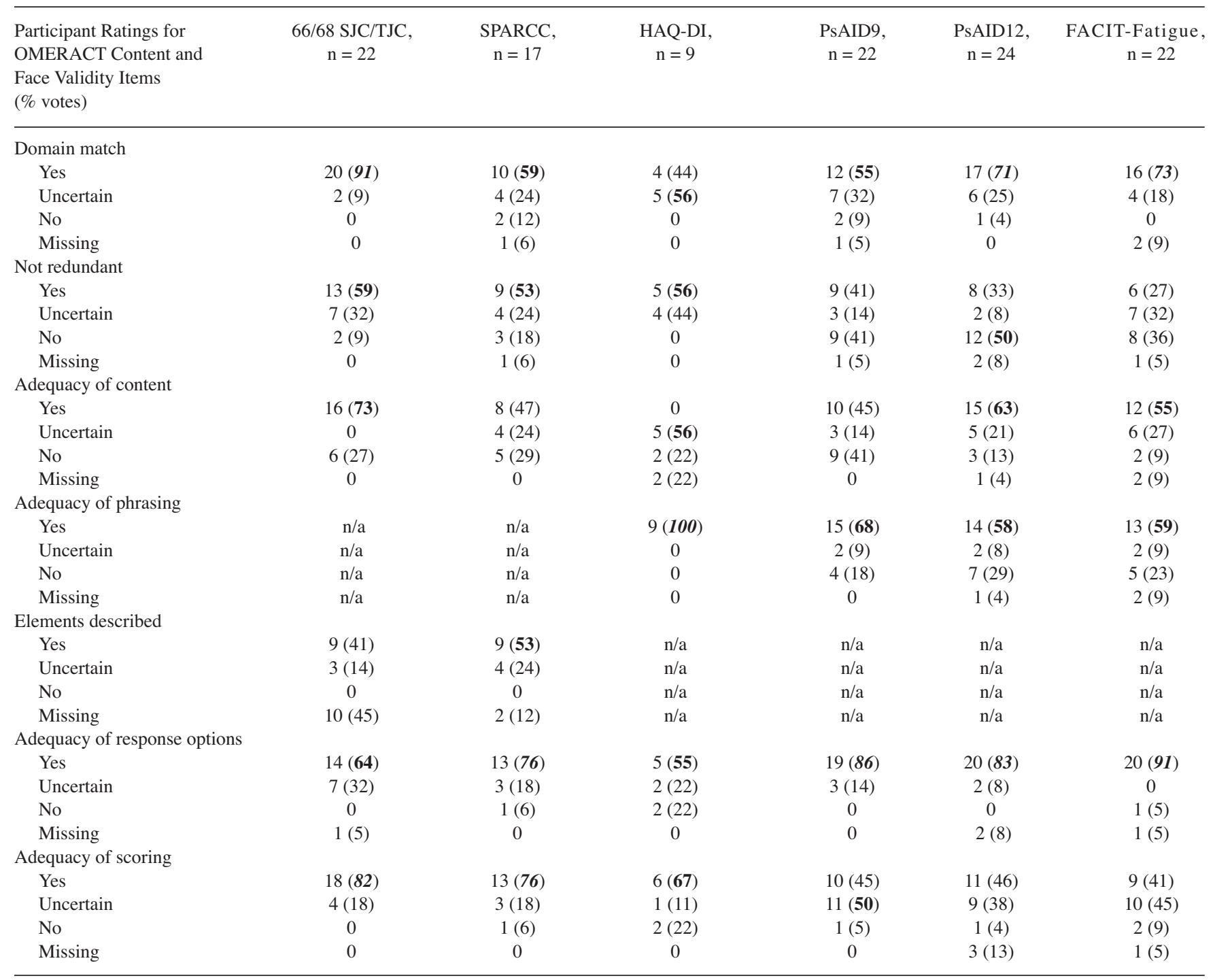

Bold and italic indicate consensus ( $\geq 70 \%$ ); bold only indicates majority agreement $(\geq 50 \%$ but $<70 \%)$. GRAPPA: Group for Research and Assessment of Psoriasis and Psoriatic Arthritis; OMERACT: Outcome Measures in Rheumatology; PsA: psoriatic arthritis; SJC/TJC: swollen/tender joint count; SPARCC: Spondyloarthritis Consortium of Canada; HAQ-DI: Health Assessment Questionnaire-Disability Index; PsAID: Psoriatic Arthritis Impact of Disease; FACIT: Functional Assessment of Chronic Illness Therapy; n/a: not applicable.

administration, and equipment needs were found adequate (by $64-100 \%$ in each group) for all 6 instruments considered. The majority voted that cost, copyright, and availability in languages needed were feasible for 66/68 SJC/TJC, SPARCC, HAQ-DI, PsAID9, and PsAID12. Participants felt they needed more information on these aspects for FACIT-Fatigue.

A facilitated discussion was held of content/face validity and feasibility while addressing the OMERACT criteria. Important considerations from breakout group discussions are summarized for each instrument in Table 3. A show of hands vote that was taken at the end of the breakout group discussions is summarized in Table 4.
OMERACT process. Participants reported that the domain matching process was complex and that contextual/ confounding factors (Table 3 shows examples) play an important role when instrument to domain match is assessed. Although some contextual/confounding factors are accounted for in clinical trials, it is important to carefully consider these at the stage of clinical trial design for each study population, intervention, and outcome of interest. Domain definitions and patient quotes, where applicable, were found generally helpful. In addition, for instruments in which technique was important (66/68 SJC/TJC), there was a suggestion to use demonstrational videos in addition to or instead of printed materials. When voting for domain match and feasibility, 
Table 2. GRAPPA meeting participants' ratings for OMERACT feasibility questionnaires for each PsA instrument.

\begin{tabular}{|c|c|c|c|c|c|c|}
\hline $\begin{array}{l}\text { Participant Ratings for } \\
\text { OMERACT Feasibility Items } \\
\text { (\% votes) }\end{array}$ & $\begin{array}{c}\text { 66/68 SJC/TJC } \\
\mathrm{n}=22\end{array}$ & $\begin{array}{c}\text { SPARCC, } \\
\mathrm{n}=17\end{array}$ & $\begin{array}{c}\text { HAQ-DI, } \\
n=9\end{array}$ & $\begin{array}{c}\text { PsAID9, } \\
\mathrm{n}=21\end{array}$ & $\begin{array}{l}\text { PsAID12, } \\
\mathrm{n}=24\end{array}$ & $\begin{array}{l}\text { FACIT-Fatigue, } \\
\quad \mathrm{n}=22\end{array}$ \\
\hline Yes & $19(86)$ & $7(41)$ & $7(78)$ & $12(57)$ & $14(\mathbf{5 8})$ & $17(77)$ \\
\hline Uncertain & $1(5)$ & $2(12)$ & $2(22)$ & $6(29)$ & $3(13)$ & $2(9)$ \\
\hline No & 0 & 0 & 0 & $3(14)$ & $5(21)$ & $2(9)$ \\
\hline Yes & $14(64)$ & $15(88)$ & $8(89)$ & $18(86)$ & $18(75)$ & $18(82)$ \\
\hline Uncertain & $7(32)$ & $2(12)$ & 0 & $3(14)$ & $3(13)$ & $3(14)$ \\
\hline No & 0 & 0 & $1(11)$ & 0 & $1(4)$ & 0 \\
\hline Missing & $1(5)$ & 0 & 0 & 0 & $2(8)$ & $1(5)$ \\
\hline \multicolumn{7}{|l|}{ Method of administration feasible } \\
\hline Yes & $19(86)$ & $17(100)$ & $7(78)$ & $19(90)$ & $21(88)$ & $20(91)$ \\
\hline Yes & $20(91)$ & $15(88)$ & $9(100)$ & $16(76)$ & $16(67)$ & $5(23)$ \\
\hline Uncertain & $1(5)$ & $2(12)$ & 0 & $5(24)$ & $6(25)$ & $16(73)$ \\
\hline No & 0 & 0 & 0 & 0 & 0 & 0 \\
\hline Missing & $1(5)$ & 0 & 0 & 0 & $2(8)$ & $1(5)$ \\
\hline \multicolumn{7}{|l|}{ Copyright issues feasible } \\
\hline Yes & $13(\mathbf{5 9})$ & $10(\mathbf{5 9})$ & $7(78)$ & $15(71)$ & $14(58)$ & $7(32)$ \\
\hline Uncertain & $3(14)$ & $1(6)$ & $1(11)$ & $4(19)$ & $6(25)$ & $14(64)$ \\
\hline No & $3(14)$ & $3(18)$ & $1(11)$ & $2(10)$ & $2(8)$ & 0 \\
\hline Missing & $3(14)$ & $3(18)$ & 0 & 0 & $2(8)$ & $1(5)$ \\
\hline \multicolumn{7}{|l|}{ Equipment needs feasible } \\
\hline Yes & $16(73)$ & $13(76)$ & $9(100)$ & $18(86)$ & $19(79)$ & $14(64)$ \\
\hline Uncertain & $3(14)$ & $2(12)$ & 0 & $3(14)$ & $3(13)$ & $5(23)$ \\
\hline
\end{tabular}

Bold and italic indicate consensus ( $\geq 70 \%$ ); bold only indicates majority agreement $(\geq 50 \%$ but $<70 \%)$. GRAPPA: Group for Research and Assessment of Psoriasis and Psoriatic Arthritis; OMERACT: Outcome Measures in Rheumatology; PsA: psoriatic arthritis; SJC/TJC: swollen/tender joint count; SPARCC: Spondyloarthritis Consortium of Canada; HAQ-DI: Health Assessment Questionnaire-Disability Index; PsAID: Psoriatic Arthritis Impact of Disease; FACIT: Functional Assessment of Chronic Illness Therapy.

participants asked whether the appraisal process would be best performed for each instrument individually versus examining multiple instruments concomitantly and comparatively that measure the same domain. Participants found the group discussion process essential in evaluating candidate instruments.

\section{DISCUSSION}

PsA is a rheumatologic disease manifesting with arthritis, enthesitis, dactylitis, axial arthritis, and skin and nail psoriasis. There is significant variability among individuals with PsA in their combination of clinical manifestations, response to treatment, prognosis, and reported life effect, which makes the comprehensive assessment of this disease especially important in both RCT and LOS. Disease hetero- geneity and timeline for availability of instruments for disease-specific manifestations (e.g., dactylitis, enthesitis) has resulted in the use of a multitude of instruments and a relative lack of standardization across RCT and LOS. The updated PsA core domain set has now defined which core domains should be assessed routinely in RCT, and the GRAPPA-OMERACT PsA working group is developing a core instrument set to measure these domains.

At the GRAPPA 2017 annual meeting, the working group completed the first 2 steps of the OMERACT instrument selection process (domain match and feasibility) for 5 candidate instruments, and 145 GRAPPA members participated in a workshop and breakout group discussions. GRAPPA participants selected the first set of candidate instruments to undergo the OMERACT Filter 2.1 construct

Personal non-commercial use only. The Journal of Rheumatology Copyright @ 2018 . All rights reserved. 
Table 3. Important arguments for and against for each instrument as discussed by participants in breakout groups.

\begin{tabular}{llll}
\hline Breakout Group & Instrument & Pros & \multicolumn{1}{c}{ Cons } \\
\hline $\begin{array}{l}\text { MSK disease activity }- \\
\text { Arthritis }\end{array}$ & $66 / 68$ SJC/TJC & $\begin{array}{l}\text { Standard of measurement of active joints } \\
\text { in clinical trials }\end{array}$ & $\begin{array}{l}\text { Potential for TJC to be confounded by } \\
\text { comorbidities including osteoarthritis and } \\
\text { fibromyalgia. }\end{array}$ \\
& & $\begin{array}{l}\text { Lack of clarity of definition. } \\
\text { Time to perform. }\end{array}$
\end{tabular}

MSK disease activity - SPARCC

Enthesitis

Patient global

GRAPPA patient global

OMERACT patient global

Physical function

HAQ-DI

PsAID9 and PsAID12

Health-related
life/life effect

Fatigue

FACIT-Fatigue
Relates well to pain at the entheses. Feasible and quick to perform.

Assesses patient global over the preceding week.

Defines "arthritis" and "skin disease" separately.

Feasible - easy to administer

Widely used PROM

Strong face and content validity from being developed through a robust, multinational mixed methods study with extensive patient involvement. Feasible, although could be improved with electronic version.

Questions worded both ways (positive and negative) may increase responder attention and improve precision
May not reflect purely inflammatory pathology and may measure other disease aspects (tender joints, overlying psoriasis).

Tenderness may reflect pain from other etiologies (fibromyalgia).

Developed using imaging data; selected points may not be clinically tender sites.

May be difficult/less exact in overweight patients.

Assesses patient global only at a single timepoint.

\begin{abstract}
May not be disease-specific and could be influenced by comorbidities.

Questions may not be relevant to all patients. Not all aspects of physical function included (e.g., high-intensity physical activity). Could be complemented by performance-based physical function assessment.
\end{abstract}
Questionnaire wording may confuse some patients, particularly the use of the term psoriatic arthritis when referencing skin disease. Does not include all aspects of domain, for example sexual function.
May not be relevant for all cultures.
Alternating positively and negatively worded questions can be confusing to respondents. Redundancy, with some questions identical except the term used to describe fatigue. Seems long, and scoring is complex.
May not translate well in languages where there is only one word for fatigue.
Interpretation of each question may be different across languages.

MSK: musculoskeletal; SJC/TJC: swollen/tender joint count; SPARCC: Spondyloarthritis Consortium of Canada; GRAPPA: Group for Research and Assessment of Psoriasis and Psoriatic Arthritis; OMERACT: Outcome Measures in Rheumatology; HAQ-DI: Health Assessment Questionnaire-Disability Index; PROM: patient-reported outcome measures; PsAID: Psoriatic Arthritis Impact of Disease; FACIT: Functional Assessment of Chronic Illness Therapy.

validity and discrimination appraisal: 66/68 SJC/TJC, SPARCC, PsAID9, PsAID12, HAQ-DI, and FACIT-Fatigue instruments. The limitations of this process were that only a limited number of instruments could be discussed within the time constraints, and only GRAPPA members who were present at the 2017 annual meeting could participate. Completion of anonymous domain match and feasibility questionnaires was limited for $\operatorname{PtGA}(n=2)$, and the process will have to be repeated with the inclusion of more participants for these instruments. Importantly, following the workshop at the GRAPPA 2017 annual meeting, GRAPPA members will participate in the assessment and rating of additional PsA measurement instruments. Based on evidence from systematic literature reviews and RCT, a multistep consensus process with relevant participants reviewing the evidence will follow with the objective of selecting the 
Table 4. Outcome of voting on domain match and feasibility for candidate outcome measurement instruments.

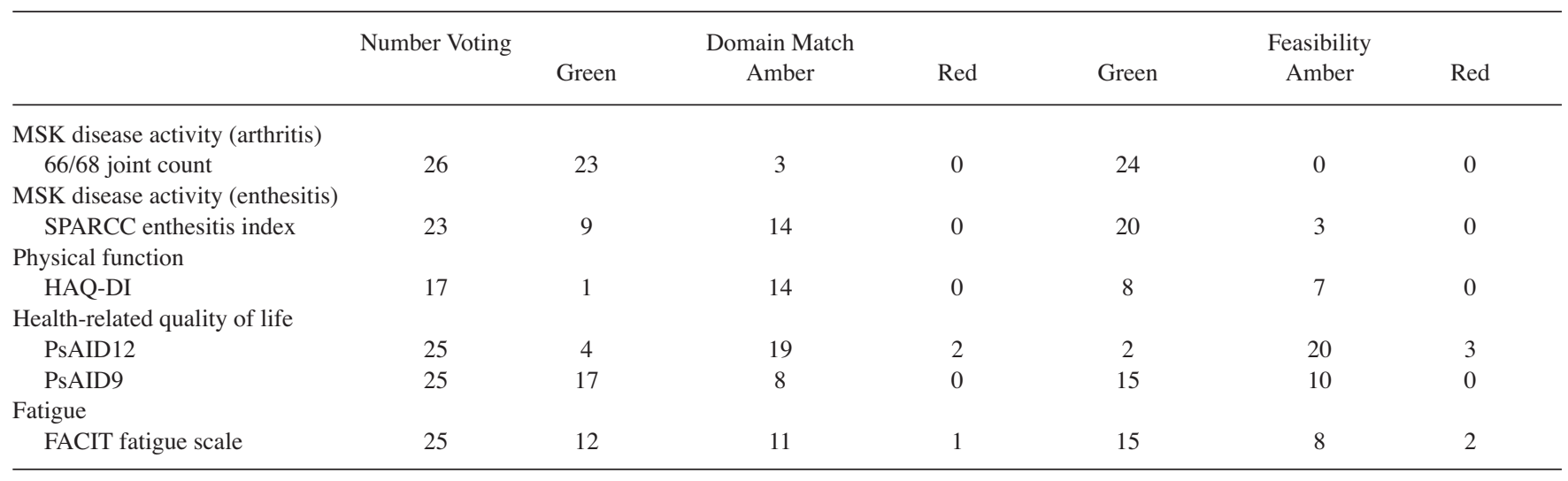

MSK: musculoskeletal; SPARCC: Spondyloarthritis Consortium of Canada; HAQ-DI: Health Assessment Questionnaire-Disability Index; PsAID: Psoriatic Arthritis Impact of Disease; FACIT: Functional Assessment of Chronic Illness Therapy.

optimal instruments to be included in the core instrument set for PsA clinical trials.

\section{ACKNOWLEDGMENT}

The authors acknowledge Ina Campbell for her participation in the workshop at the GRAPPA meeting as a patient research partner. We thank Michelle Jones from the Johns Hopkins Arthritis Center for preparing the breakout group materials and programming the steering group survey. We thank Pam Love and Sharon Andrews for their help in coordinating working group teleconferences and communications, and we thank Tori Fischer for editorial assistance.

\section{ONLINE SUPPLEMENT}

Supplementary material accompanies the online version of this article.

\section{REFERENCES}

1. Taylor W, Gladman D, Helliwell P, Marchesoni A, Mease P, Mielants $\mathrm{H}$, et al. Classification criteria for psoriatic arthritis: development of new criteria from a large international study. Arthritis Rheum 2006;54:2665-73.

2. Gladman DD, Mease PJ, Strand V, Healy P, Helliwell PS, Fitzgerald $\mathrm{O}$, et al. Consensus on a core set of domains for psoriatic arthritis. J Rheumatol 2007;34:1167-70.

3. Tillett W, Eder L, Goel N, De Wit M, Gladman DD, FitzGerald O, et al. Enhanced patient involvement and the need to revise the core set - report from the Psoriatic Arthritis Working Group at OMERACT 2014. J Rheumatol 2015;42:2198-203.

4. Orbai AM, de Wit M, Mease PJ, Callis Duffin K, Elmamoun M, Tillett W, et al. Updating the Psoriatic Arthritis (PsA) Core Domain Set: a report from the PsA Workshop at OMERACT 2016. J Rheumatol 2017;44:1522-8.

5. Boers M, Kirwan JR, Wells G, Beaton D, Gossec L, d'Agostino MA, et al. Developing core outcome measurement sets for clinical trials: OMERACT filter 2.0. J Clin Epidemiol 2014;67:745-53.

6. Orbai AM, de Wit M, Mease P, Shea JA, Gossec L, Leung YY, et al. International patient and physician consensus on a psoriatic arthritis core outcome set for clinical trials. Ann Rheum Dis 2017;76:673-80.
7. Tillett W, Orbai AM, Ogdie A, Leung YY, Strand V, Gladman DD, et al. GRAPPA-OMERACT initiative to standardise outcomes in psoriatic arthritis clinical trials and longitudinal observational studies. Ann Rheum Dis 2017 Jul 26 (E-pub ahead of print).

8. Boers M, Kirwan JR, Tugwell P, Beaton D, Bingham CO III, Conaghan PG, et al. The OMERACT Handbook. [Internet. Accessed February 8, 2018.] Available from: www.omeract.org/resources

9. Hojgaard P, Klokker L, Orbai AM, Holmsted K, Bartels EM, Leung YY, et al. A systematic review of measurement properties of patient reported outcome measures in psoriatic arthritis: A GRAPPA-OMERACT initiative. Semin Arthritis Rheum 2017 Sep 9 (E-pub ahead of print).

10. Felson DT, Anderson JJ, Boers M, Bombardier C, Chernoff M, Fried B, et al. The American College of Rheumatology preliminary core set of disease activity measures for rheumatoid arthritis clinical trials. The Committee on Outcome Measures in Rheumatoid Arthritis Clinical Trials. Arthritis Rheum 1993;36:729-40.

11. Maksymowych WP, Mallon C, Morrow S, Shojania K, Olszynski WP, Wong RL, et al. Development and validation of the Spondyloarthritis Research Consortium of Canada (SPARCC) Enthesitis Index. Ann Rheum Dis 2009;68:948-53.

12. Cauli A, Gladman DD, Mathieu A, Olivieri I, Porru G, Tak PP, et al. Patient global assessment in psoriatic arthritis: a multicenter GRAPPA and OMERACT study. J Rheumatol 2011;38:898-903.

13. Fries JF, Spitz PW, Young DY. The dimensions of health outcomes: the health assessment questionnaire, disability and pain scales. J Rheumatol 1982;9:789-93.

14. Gossec L, de Wit M, Kiltz U, Braun J, Kalyoncu U, Scrivo R, et al. A patient-derived and patient-reported outcome measure for assessing psoriatic arthritis: elaboration and preliminary validation of the Psoriatic Arthritis Impact of Disease (PsAID) questionnaire, a 13-country EULAR initiative. Ann Rheum Dis 2014;73:1012-9.

15. Cella D, Lai JS, Chang CH, Peterman A, Slavin M. Fatigue in cancer patients compared with fatigue in the general United States population. Cancer 2002;94:528-38. 
APPENDIX 1. Patient quotes from international focus groups describing their experience of fatigue and psoriatic arthritis.

Definition: Experiencing fatigue, tiredness, lack of energy, feeling worn out or exhausted.

Fatigue

* During the day I feel like sleeping, in the morning, and if I allow myself to and don't have anything to do, I go to sleep, but the tiredness is as though I'd been working hard. At times I cry because I want to do things, I'm used to doing my housework. I do it, but it's not like it was before. It wears me out a lot. I get tired. (Brazil)

* There are two sorts of fatigue, the physical fatigue originating from the pain and then you have the mental and emotional fatigue. For instance, the people around you, like your friends and family, they know it but do not fully understand it. You always have to pretend to be cheerful. (France)

* When I'm having a flare or when I'm just generally not doing better, not under control or need an adjustment in my medicine the fatigue is a lot worse, and I can just tell a difference. I just feel more tired or I don't sleep as well and when I don't sleep as well I will ache the next day too, just like my joints that have activity will hurt more, I just will always feel tired, and I could come home from work and go right to bed. That's not like me, I'm a very active person. (USA)

* I think everyone is suffering from fatigue, from whether or not there is understanding and you can't do some things. That I find myself very difficult and if you're used to wanting everything and doing everything you want, you never look exactly for how far you can go. And then you go too far. So you always have regrets afterwards and you think, oh I will pay better attention next time. But you don't do that, you just keep going on. Because if I would not do that then I would feel very weird in life. So you just keep going on. I think everyone actually does that with such a disease. (Netherlands)

\section{Copyright 1987, 1997; reprinted with permission, FACIT.org}

APPENDIX 2. FACIT fatigue tool and scoring guidelines.

Domain: Fatigue

Definition: Experiencing fatigue, tiredness, lack of energy, feeling worn out or exhausted

\section{Tool: FACIT-Fatigue, PROMIS Short Form v1.0 - Fatigue 13a (FACIT-Fatigue)}

How the tool is used: This is a patient-reported outcome. The patient completes the questionnaire. Item response values in the short form are logged as below under Item response and the operation is performed (the item response is subtracted from 4, except for items An5 and An7, the item response is kept as is). Item scores are calculated as below and added together to obtain the raw score. This is then multiplied by 13 and then divided by the total number of answered item (see scoring table below). The score range is 0-52. Higher scores mean less fatigue.

Scoring ${ }^{1}$

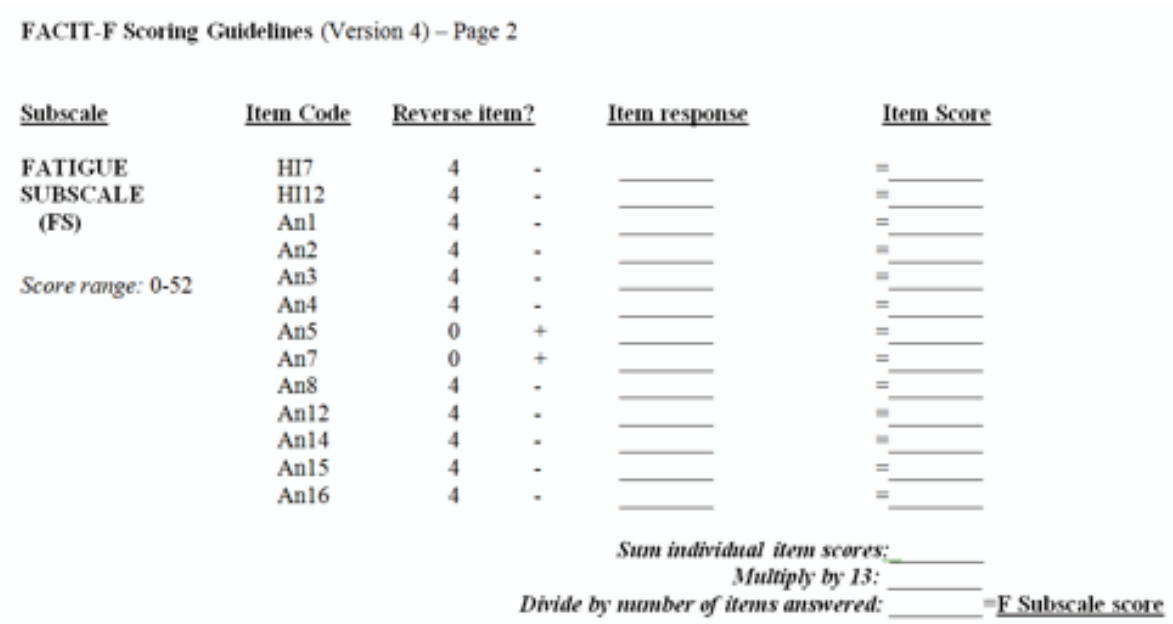

Important: the FACIT-Fatigue can now also be scored as a PROMIS instrument using T scores referenced to US population norms (see PROMIS Fatigue 7a).

PsA: psoriatic arthritis; FACIT: Functional Assessment of Chronic Illness Therapy; PROMIS: Patient Reported Outcomes Measurement Information System; FS: fatigue subscale.

1. Cella D, Lai JS, Chang CH, Peterman A, Slavin M. Fatigue in cancer patients compared with fatigue in the general United States population. Cancer 2002;94:528-38. Available from: www.FACIT.org (scoring available upon registration).

\section{Copyright 1987, 1997; reprinted with permission, FACIT.org}


Below is a list of statements that other people with your illness have said are important. Please circle or mark one number per line to indicate your response as it applies to the past 7 days.

HI7 I feel fatigued

HI12 I feel weak all over

An1 I feel listless ("washed out")

An2 I feel tired

An3 I have trouble starting things because I am tired

An4 I have trouble finishing things because I am tired

An5 I have energy

An7 I am able to do my usual activities

An8 I need to sleep during the day

An12 I am too tired to eat

An14 I need help doing my usual activities

An15 I am frustrated by being too tired to do the things I want to do

An16 I have to limit my social activity because I am tired

Not at all
0
0
0
0
0
0
0
0
0
0
0
0
0

A little bit

Somewhat

1

1

1

1

1

1

1

1

1

1

1

1

\section{Quite a bit Very much}

2
2
2
2
2
2
2
2
2
2
2
2
2

4
4
4
4
4
4
4
4
4
4
4
4
4

Copyright 1987, 1997; reprinted with permission, FACIT.org 